\title{
2015 JPBM \\ Communications Award
}

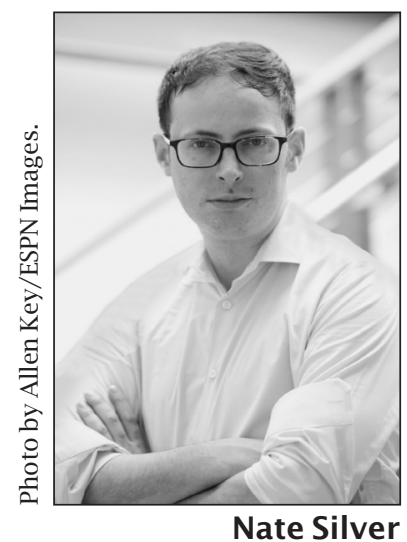

The 2015 Communications Award of the Joint Policy Board for Mathematics (JPBM) was presented at the Joint Mathematics Meetings in San Antonio, Texas, in January 2015.

The JPBM Communications Award is presented annually to reward and encourage journalists and other communicators who, on a sustained basis, bring mathematical ideas and information to nonmathematical audiences. JPBM represents the American Mathematical Society, the American Statistical Association, the Mathematical Association of America, and the Society for Industrial and Applied Mathematics. The award carries a cash prize of US $\$ 1,000$.

Previous recipients of the JPBM Communications Award are: James Gleick (1988), Hugh Whitemore (1990), Ivars Peterson (1991), Joel Schneider (1993), Martin Gardner (1994), Gina Kolata (1996), Philip J. Davis (1997), Constance Reid (1998), Ian Stewart (1999), John Lynch and Simon Singh (special award, 1999), Sylvia Nasar (2000), Keith J. Devlin (2001), Claire and Helaman Ferguson (2002), Robert Osserman (2003), Barry Cipra (2005), Roger Penrose (2006), Steven H. Strogatz (2007), Carl Bialik (2008), George Csicsery (2009), Marcus du Sautoy (2010), Nicolas Falacci and Cheryl Heuton (2011), Dana Mackenzie (2012), John Allen Paulos (2013), and Danica McKellar (2014).

\section{Citation}

The 2015 JPBM Communications Award was presented to NATE SILVER for his award-winning FiveThirtyEight. com website, his New York Times best-seller The Signal and the Noise: Why Most Predictions Fail-But Some Don't (2012), and a host of other ways in which he has helped the public to better understand the world through sound and innovative use of statistics and extraordinarily lucid explanations of his work.

\section{Biographical Sketch}

Nate Silver is a leading statistician and bestselling author known for his unique brand of creativity, journalism, and statistical analysis. $\mathrm{He}$ is the founder of the award-winning website FiveThirtyEight, which was acquired by ESPN in 2013. The site relaunched as an ESPN entity on March 17, 2014, and expanded its coverage to include topics such as sports, economics, culture, science and technology, among others. FiveThirtyEight continues to provide data-driven coverage of politics, including forecasts of upcoming elections.

Silver has established himself as today's leading statistician through his innovative analyses of political polling. He first gained national attention during the 2008 presidential election, when he correctly predicted the results of the presidential election in forty-nine of fifty states, along with all thirty-five US Senate races. In 2012 FiveThirtyEight predicted the election outcome in all fifty states. FiveThirtyEight has made Silver the public face of statistical analysis and political forecasting.

Before he came to politics, Silver established his credentials as an analyst of baseball statistics. He developed a widely acclaimed system called PECOTA (Player Empirical Comparison and Optimization Test Algorithm), which predicts player performance, career development, and seasonal winners and losers. He is a coauthor of a series of books on baseball statistics, which include Mind Game, Baseball between the Numbers, and It Ain't Over 'til It's Over. Silver has written for ESPN. com, Sports Illustrated, Slate, Baseball Prospectus, Newsweek, The New York Post, and The Los Angeles Times.

Silver has earned a series of accolades. Fast Company chose him as No. 1 on their list of the 100 Most Creative People in Business 2013. He was among Time magazine's 100 Most Influential People of 2009 and Rolling Stone magazine's 100 Agents of Change. In 2012 and 2013, FiveThirtyEight won Webby Awards as the best political blog.

-JPBM announcement 